\title{
Alternativas de rastreo de cáncer de cuello uterino en poblaciones con baja accesibilidad a los servicios de salud
}

Goldie y col. N Engl J Med. 2005;353:2158-68.

Objetivo

Evaluar la costo-efectividad de diversas estrategias de diagnóstico y tratamiento del cáncer de cuello uterino.

Diseño

Análisis de costo-efectividad.

Lugar

Se utilizaron datos provenientes de cinco países en vías de desarrollo: India, Kenia, Perú, Sudáfrica y Tailandia.

\section{Pacientes}

Se simuló la historia natural de una neoplasia cervical por el virus del papiloma humano (HPV) mediante la utilización de un modelo de computación. Se consideró la realización de una consulta a los 35 años y luego consultas periódicas cada cinco años. Se asumió que la consulta sería realizada en un centro de atención primaria.

\section{Intervención}

Se comparó: 1) colposcopía; 2) Papanicolau; 3) Captura híbrida del HPV; 4) Estrategia combinada de colposcopía y captura híbrida de HPV. Además, se consideró la posibilidad de realizar una sola consulta (diagnóstico y tratamiento el mismo día) dos consultas (diagnóstico en primera consulta y tratamiento en la segunda) o tres consultas (diagnóstico en la primera, colposcopía y biopsia en la segunda, y tratamiento en la tercera). Se asumió que los tratamientos de las estrategias de una y dos consultas se realizarían con criocirugía (a excepción de aquellos casos en los que, por extensión de la lesión, se derivaran a un centro de segundo nivel).
Los tratamientos de las estrategias de tres visitas se realizarían en centros de derivación.

\section{Medición de costos y resultados principales}

Cuando se realiza una colposcopía o una captura híbrida de HPV en una sola visita, la reducción del riesgo de cáncer cervical invasor es del $25 \%$ y $30 \%$ respectivamente. En el caso del papanicolau, cuando se realizan dos visitas es del 18\%. La realización de un segundo control a los 40 años reduce el riesgo en un $40 \%$ aproximadamente, mientras que un tercer control reduce el riesgo en un $15 \%$ más.

En todos los casos, al realizar una visita a los 35 años con colposcopía o HPV en una sola consulta, el costo por año de vida salvado no supera los 500 dólares. La realización de más consultas a lo largo de la vida aumenta la efectividad, con un aumento marginal de los costos. En todos los casos, la captura híbrida de HPV en una visita, tres veces en la vida, constituye la estrategia más efectiva con un costo por año de vida salvado entre 591 y 2458 dólares, según el país. El análisis de sensibilidad no mostró cambios significativos en el orden de costo-efectividad de las diversas estrategias.

\section{Conclusiones}

La captura híbrida de HPV y la colposcopía constituyen métodos de rastreo costo-efectivos en poblaciones de bajos recursos y con baja tasa de seguimiento.

Fuente de financiamiento: Bill and Melinda Gates Foundation

\section{Comentario}

El cáncer de cuello uterino es una de las patologías oncológicas más prevenibles dado que presenta lesiones premalignas fácilmente detectables y tratables, y que cursan con un tiempo de evolución natural prolongado. En Argentina, en 1999, la tasa de mortalidad ajustada por edad de cáncer de cuello uterino fue de 4,46 por cada 100.000 mujeres.

El papanicolau se realiza hace más de 30 años en Argentina, pero la cobertura a nivel poblacional es muy baja, estimada entre el 15 y $25 \%$ según los lugares ${ }^{1}$. Por otra parte, la prevalencia de HPV es de alrededor del $18 \%$ en mujeres sexualmente activas ${ }^{2}$.

Este estudio evaluó mediante un diseño metodológicamente adecuado diversas estrategias para el diagnóstico y el tratamiento de esta patología en países en vías de desarrollo donde el tamizaje se realizaría sólo una, dos o tres veces a lo largo de la vida. Debido a esto, las conclusiones que surgen de este estudio sólo deberían ser aplicadas a una población en la que se dificulta realizar un seguimiento adecuado ${ }^{3}$ de acuerdo a las recomendaciones internacionales. Los aspectos que hicieron más costo-efectivas a las diversas estrategias fueron aquellos que garantizaban el tratamien- to de las lesiones mediante un número reducido de visitas al médico con la consecuente reducción en la pérdida de seguimiento. Si bien los costos son diferentes en los diferentes países, en todos los casos fueron menores que el producto bruto interno por habitante, parámetro comúnmente utilizado para comparar estrategias en diferentes medios. La captura híbrida de HPV resultó ser la estrategia más costo-efectiva, aunque requiere de la posibilidad de correr el estudio el mismo día en que se realiza.

\section{Conclusiones del comentador}

En nuestro medio, principalmente en aquellos centros donde el seguimiento anual es improbable, debe considerarse la realización sistemática de la colposcopía y, cuando sea posible, la captura híbrida de HPV. Es importante tener en cuenta cuáles son los recursos disponibles en cada región para evaluar la aplicabilidad de estos resultados.

Demián Glujovsky [ Coordinador del Programa de Ovodonación. Centro de Estudios en Ginecología y Reproducción. ]

Glujovsky D. Alternativas de rastreo de cáncer de cuello uterino en poblaciones con baja accesibilidad a los servicios de salud. Evid. actual. páct. ambul. 9(3);68. May-Jun. 2006. Comentado de: Goldie S, Gaffikin L, Goldhaber J y col. Cost-effectiveness of cervical-cancer screening in five developing countries. N Engl J Med. 2005;353:2158-68. PMID: 16291985.

\section{Referencias}

1. Rocco D. Mortalidad por cáncer de útero en Argentina. Ministerio de Salud de la Nación Subsecretaría de Investigación y Tecnología Administración Nacional de Laboratorios e Institutos de Salud "Dr. Carlos G. Malbran"

2. Matos E, Loria D, Amestoy GM y col. Prevalence of human papillomavirus infection among women in Concordia, Argentina: a population-based study. Sex Transm Dis. 2003 Aug; 30(8):593-9.

3. ACOG Practice Bulletin. Clinical Management Guidelines for Obstetrician-Gynecologists. Human papillomavirus. Number 61, April 2005. Obstet Gynecol. 2005;105(4):905-18. 